\title{
A razão ética e poética nos poemas de Ana Martins Marques
}

Anélia Montechiari Pietrani ${ }^{1}$

O poema aprende com o mar

a colocar os corpos em perigo.

Ana Martins Marques

Estudar a literatura contemporânea é desafiar-se constantemente diante de uma obra que está em curso, buscando - no discurso caudaloso de certezas e incertezas - a unidade que faz - no fazendo - a obra. Significa também assumir os riscos que essa tarefa impõe: a tarefa de talvez só descrever e ser imparcial demais; a tarefa de analisar arrogando-se à terrível certeza - perigosíssima - das respostas e do marco zero; a tarefa de julgar, e julgar com a paixão à flor da pele e no calor da hora. Aceitando, porém, o repto, propomos esta leitura, também em curso, sobre a poetisa mineira Ana Martins Marques, tomando como ponto de partida a reflexão suscitada pela palavra poética de seu conterrâneo João Guimarães Rosa:

Sionésio e Maria Exita - a meios-olhos, perante o refulgir, o todo branco. Acontecia o não-fato, o não-tempo, silêncio em sua imaginação. Só o um-e-outra, um em-si-juntos, o viver em ponto sem parar, coraçãomente, pensamento, pensamôr. Alvor. Avançavam, parados, dentro da luz, como se fosse no dia de Todos os Pássaros (Rosa, 2005, p. 190).

No último parágrafo de "Substância", conto integrante do livro Primeiras estórias, obra originalmente publicada em 1962, Guimarães Rosa apresenta as palavras que marcariam o amor de Maria Exita e Sionésio. Marca de sedução poética do discurso de Rosa, que aglutina erótica e intelectivamente as palavras em-si-juntas, o conto "Substância", em seu desfecho, desconstruindo-o no espaço e no tempo do enredo e construindo-o na própria linguagem, nos faz refletir sobre qual é a medida (ou desmedida) da razão no ato de escritura poética. Ao modo do coração, rosianamente dito "coraçãomente", a vida, o amor, a poesia em sua linguagem só se realizam se forem nomeados em "pensamôr".

\footnotetext{
${ }^{1}$ Doutora em literatura comparada e professora da Universidade Federal do Rio de Janeiro (UFRJ), Rio de Janeiro, RJ, Brasil. E-mail: aneliapietrani@letras.ufrj.br
} 
Tomando por caminho as veredas desse grande sertão da linguagem rosiana como mote deste trabalho, propomos a leitura de poemas de Ana Martins Marques dos seus dois livros publicados até então, A vida submarina (2009) e Da arte das armadilhas (2011), em que os sentidos e as razões do ato poético se conjugam numa tal rede de sensualidade e intelectividade que nos levam à reflexão sobre o papel, o valor e o lugar da poesia na contemporaneidade.

Nascida em Belo Horizonte em 1977, Ana Martins Marques já coleciona prêmios: em 2007, aos 30 anos, ganhou o Prêmio Cidade de Belo Horizonte, na categoria Poesia - autor estreante, e, em 2008, recebeu o mesmo prêmio, na categoria Poesia. A vida submarina, seu livro de estreia, reúne uma seleção dos poemas premiados nesses concursos. Seu livro Da arte das armadilhas, que já havia sido finalista do Prêmio Portugal Telecom 2012, recebeu o Prêmio Biblioteca Nacional de Literatura na categoria Poesia - 2012. Diferentemente de seu primeiro livro, publicado pela Scriptum, uma pequena editora em Belo Horizonte, $\mathrm{Da}$ arte das armadilhas tem uma trajetória diferente. Foi publicado por uma grande editora comercial, a Companhia das Letras, e recebeu orelha assinada pelo poeta Armando Freitas Filho, que assim escreve sobre a poetisa e seu livro:

A poesia de AMM tem um sequenciamento que exige de AFF esse continuum. Não dá para largar ou intercalar. Apesar de não conhecê-la, me sinto próximo da poeta. Parece que ela está sentada ao meu lado escrevendo/dizendo no meu ouvido o que tem de mais íntimo, nos seus variados acentos, vida afora (Freitas Filho apud Marques, 2011, orelha).

É essa relação de diálogo entre poeta e leitor, de identificação e adesão colada ao corpo e à letra de AMM e AFF, que podemos observar na poesia de Ana Martins Marques. A poesia de aparência fácil, de temática prosaica, com ritmo leve, de versos curtos e concisos de Ana Martins, não nos permite largar o livro, como diz Armando Freitas Filho. Sua poesia tem continuidade, um caminho narrativo, um diálogo que não cessa, que se enreda cada vez mais, um trânsito entre um "eu" e um "você", que é, às vezes, o amor, o ser amado; outras, a linguagem, a palavra, a arte da palavra, ser também amado. Redes, tramas, tecidos, enredos, prisões, presas, caças, caçadores, armadilhas do amor e da arte, com seus riscos e perigos - são estes alguns dos elementos da poesia de Ana Martins Marques. 


\title{
Redes de Penélope
}

\author{
Também \\ a quem fica \\ cabe uma paisagem nova \\ e a travessia insone do desconhecido \\ e a alegria difícil da descoberta. \\ O que levas do que fica, \\ o que, do que levas, retiro?
}

Ana Martins Marques

Imagem-personagem recorrente dos dois livros de Ana Martins Marques, Penélope, com seus tecidos de amor e suas armadilhas de linguagem, dá título a seis poemas numerados de $A$ vida submarina. Lidos em sequência, ainda que eles sejam distribuídos ao longo do livro, percebe-se neles sua carga de narratividade. Os títulos dos segmentos em que se incluem também são significativos: os poemas I e II aparecem em "Exercícios para a noite e o dia"; o III, em "Caderno de caligrafia"; e o IV, V e VI, na última parte, que tem título homônimo ao livro: "A vida submarina".

Poesia escrita como exercício permanente, sentida como pensamento dianoturnamente, tecida como risco da linha no papel e construída como rede dos perigos do mar, seja em ausência, seja como desejo, os poemas de A vida submarina aproximam-se do que M. H. Abrams chama de "a quarta dimensão do poema". Em conferência na Cornell University, em 2010, Abrams definiu a "quarta dimensão", que, segundo ele, é algo que é praticamente neglicenciado em discussões sobre poesia, como a grande variedade de "sons do discurso" que constituem o poema, o corpo material da poesia que transporta seus significados não materiais. Diz Abrams:

Nós produzimos esses sons variando a pressão dos pulmões, vibrando ou estendendo as cordas vocais, mudando a forma da garganta e da boca e fazendo, maravilhosamente, precisos movimentos da língua e dos lábios. Pode ser dito, então, que a produção física de um poema começa próximo ao coração e termina perto do cérebro. Essa é uma razão [de se dizer] que poesia é sentida como a mais intimista das artes, além de ser a mais abrangente e variada em expressar o que é humano (Abrams, 2012, p. 2, tradução nossa). 
Refletindo entre o que é íntimo e totalizante, pondo sob discussão o particular e o universal da poesia, com início no coração e fim no cérebro, demasiadamente humanos, assim como é humana a poesia, passemos à leitura dos seis poemas "Penélopes", de Ana Martins Marques, em A vida submarina:

\section{Penélope (I)}

O que o dia tece a noite esquece.

O que o dia traça a noite esgarça.

De dia, tramas, de noite, traças.

De dia, sedas, de noite, perdas.

De dia, malhas, de noite, falhas (Marques, 2009, p. 89).

\section{Penélope (II)}

A trama do dia

na urdidura da noite

ou a trama da noite

na urdidura do dia

enquanto teço:

a fidelidade por um fio (Marques, 2009, p. 105).

\section{Penélope (III)}

De dia dedais.

Na noite ninguém (Marques, 2009, p. 125).

\section{Penélope (IV)}


E ela não disse

já não te pertenço

há muito entreguei meu coração ao sossego

enquanto seu coração balançava em viagem

enquanto eu me consumia

entre os panos da noite

você percorria distâncias insuspeitadas

corpos encantados de mulheres com cujas línguas

estranhas eu poderia tecer uma mortalha

da nossa língua comum.

E ela não disse

no início ainda pensei em você

primeiro como quem arde diante de uma fogueira

apenas extinta

depois como quem visita em lembrança a praia da infância

e então como quem recorda o amplo verão

e depois como quem esquece.

E ela também não disse

a solidão pode ter muitas formas,

tantas quantas são as terras estrangeiras,

e ela é sempre hospitaleira (Marques, 2009, p. 134).

\section{Penélope (V)}

A viagem pela espera

é sem retorno.

Quantas vezes a noite teceu

a mortalha do dia,

quantas vezes o dia

desteceu sua mortalha?

Quantas vezes ensaiei o retorno -

o rito dos risos,

espelho tenro, cabelos trançados,

casa salgada, coração veloz?

A espera é a flor que eu consigo.

Água do mar, vinho tinto - o mesmo copo (Marques, 2009, p.

140).

\section{Penélope (VI)}


E então se sentam

lado a lado

para que ela lhe narre

a odisseia da espera (Marques, 2009, p. 142).

Cada dístico de "Penélope I" se subdivide em versos cujas imagens são contrárias. Marcadas pela antítese dia e noite, as estrofes são arrumadas em rimas emparelhadas: tece/esquece; traça/esgarça; tramas/traças; sedas/perdas; malhas/falhas. As palavras representativas do dia - tece; traça; tramas; sedas; malhas - são todas elas ligadas ao campo semântico de tecido, costura, rede, enredo, trazendo à lembrança o étimo comum a tecido e texto: o verbo texere; $\mathrm{o}$ substantivo textum, $i$. As representativas da noite - esquece; esgarça; traças; perdas; falhas - ligam-se ao campo semântico de desconstrução, destecido, destexto. Até essa primeira leitura, o poema é simples, e a imagem é corrente: a alusão direta à relação entre escrever e tecer tomada de empréstimo da figura de Penélope.

O poema, no entanto, não fica só nisso. Tem ainda mais dois aspectos que merecem ressalva: os dísticos 3 e 5 apresentam uma ambiguidade curiosa quanto à flutuação categorial de tramas/traças e malhas/falhas, que podem ser tanto substantivos plurais, como também verbos: tu tramas/ tu traças; tu malhas/ tu falhas. O segundo aspecto a se considerar tem relação direta com a classificação das rimas presentes no poema: consoantes nos dísticos 1 e 5 ; toantes (assonantes) com ligeira modificação nos dísticos 2 e 4; e toantes no dístico 3.

As rimas de coincidência perfeita de fonemas das estrofes do início e do fim do poema sofrem ligeira modificação com o acréscimo do /r/ nas toantes dos dísticos 2 e 4, para chegar à chave do poema, que, a nosso ver, está no dístico 3 - não à toa, o dístico central. Lidos como verbos da segunda pessoa do singular (tu tramas/ tu traças), a diferença fônica das rimas se contrapõe à semelhança total da primeira sílaba de cada uma das palavras (- tra) e à similitude semântica entre os verbos tramar e traçar. O poema deixa de ser somente palavra, som, e assume um movimento poético de dança, digamos, helicoidal, convergindo para um único eixo: já não há mais aqui diferenças entre o dia e a noite, nem entre outras supostas diferenças reveladas em uma primeira leitura.

Nesse sentido, o terceiro dístico - expandindo-se em continuidade ao movimento - vai também estabelecer relação com o último, se 
considerarmos o tu a quem parece se dirigir o eu poético nos dísticos 3 e 5: este é um tu que "trama" e "traça", e é também um tu que "malha" e "falha". Na estrofe 5, a rima é, semanticamente, relacionada em causaefeito com a terceira: se tu tramas, tu traças; logo, se tu malhas, tu falhas. É bom lembrar também o duplo sentido do verbo malhar, que, além de ter o significado de criar malhas ou redes, enredar, denota também falar mal de alguém, tomado em um sentido coloquial, marca bem característica da poesia de Ana Martins.

Está aqui a poeta crítica (e autocrítica), que revela que, se tu malhas, crias redes ou enredos e falas; logo, tu falhas: é a Penélope tecedeira descoberta em sua astúcia. Esse "tu" tecedor, por extensão, poeta, deixa de ser somente poeta e passa a ser também leitor: poeta e leitor que "malham" e "falham". Parecem-nos surgir a partir disso alguns questionamentos. Estaria aqui figurado o poeta que penetra o "reino das palavras", trazendo a ele a chave (drummondiana), certo (ou incerto) de seus erros e acertos? Ou/e estaria figurado o leitor que penetra o texto e "profana" as armadilhas do poeta?

A sequência de poemas mantém esse ritmo de dualidades e fusões de contrários, além de abarcar outros sentidos que a figuração de Penélope como mito traz para o poema: dia e noite; tecido e escritura; silêncio e línguas estranhas; solidão e terras estrangeiras; lembrança e esquecimento; desejo e fidelidade; solidão e infidelidade; viagem e espera.

No poema "Penélope IV", a conjunção aditiva " $\mathrm{e}$ " ("E ela não disse") com que é iniciado pode, de fato, sugerir a narratividade e unidade entre os poemas, mas pode também - se for considerada por seu significado de adversativa (mas) - indicar o vazio do anterior, o vazio do não dito, o silêncio do canto e do conto, a solidão da viagem da espera.

Outro poema também recupera essa imagem. Em "Penélope V", em que o jogo semântico com a preposição "por" já se estabelece nos primeiros versos (a viagem pela espera é através da espera, ou por causa da espera?), o verso "A espera é a flor que eu consigo" se torna bem significativo pela ambiguidade que carrega: "eu consigo", verbo conseguir flexionado na primeira pessoal do singular do presente do indicativo; "eu consigo", eu com você, que conjuga no mesmo sintagma o "eu" e seu amado, o "eu" poeta e o eu "leitor". Assim vai sendo construída a imagem da espera de Penélope: a de um "eu consigo", que será narrada/contada "lado a lado" entre o eu e seu amado, entre poeta e leitor, culminando no último poema dessa sequência não sequência, $\mathrm{o}$ 
"Penélope VI", de quatro versos apenas ("E então se sentam/ lado a lado/ para que ela lhe narre/ a odisseia da espera"), em que corpo a corpo, palavra a palavra, sensual e intelectivamente, narradora e ouvinte tecem e destecem, escrevem e leem, sentem e pensam, "coraçãomente", em "pensamôr", a odisseia de Penélope em sua espera.

A primeira imagem, a do senso comum, que nos ocorre quando se pensa em Penélope, é a da mulher que espera fielmente. A astuciosa Penélope, no entanto, traz muito mais do que essa imagem. Durante o processo de espera e de destecer o já-feito, o que fazia Penélope? Quando ela puxava o fio tecido, o que pensava Penélope? Fio por fio, buscava um significado para aquilo, como uma necessidade mesma, o pensamento como uma necessidade. Penélope pensava o pensamento. Essa comparação não é fortuita e tomo-a de empréstimo a Hannah Arendt, uma das maiores filósofas do século $X X$ que, sem dicotomizar a razão e a arte, melhor pensou, a nosso ver, o sentido de uma razão do/para o pensamento poético. Diz-nos Arendt, em A vida do espírito:

$\mathrm{Na}$ privacidade das notas postumamente publicadas, Kant escreveu: "Não concordo com a regra segundo a qual algo que ficou provado pelo uso da razão pura não está mais sujeito à dúvida, como se isso fosse um sólido axioma"; ou ainda: "Não compartilho a opinião segundo a qual [...], depois que se está convencido de alguma coisa, não se pode duvidar dela. $\mathrm{Na}$ filosofia pura isso é impossível. Nosso espírito tem uma aversão natural a isso". Daí se depreende que o pensamento é como a teia de Penélope: desfaz-se toda manhã o que se terminou de fazer na noite anterior. Pois a necessidade de pensar jamais pode ser satisfeita por insights supostamente precisos de "homens sábios". Essa necessidade só pode ser satisfeita pelo próprio pensamento, e os pensamentos que tive ontem irão satisfazer essa necessidade hoje apenas porque quero e porque sou capaz de pensá-los novamente (Arendt, 2010, p. 107, grifos nossos).

Penélope está, assim, na leitura que Arendt faz do mito, muito mais ligada ao futuro, ao ato de pensar - o fio que tece o tecido é também o fio do pensamento que cria e descria e torna a criar, do material para o não material ou vice e versa: "todo pensar é um re-pensar" (Arendt, 2010, p. 105). Esse fio do pensar, da razão, no sentido atribuído a esse termo por Hannah Arendt, é também o fio da escrita - sempre complexo, marcado de ambiguidades, de imagens múltiplas que se 
fazem e desfazem dia e noite, de dúvidas, de buscas de significados, de questionamentos, da razão (e da escrita) como necessidade. A poesia tem razão. A poesia é razão. Não se dissocia uma de outra.

O pensamento de Penélope, no ato de escritura e desescritura, num ato de razão, parece ser o mote do último poema da sequência de penélopes e último poema do livro $A$ vida submarina. A Penélope de "Penélope VI" é a que pensa o pensamento, é a que tem a vontade da razão, é a que conta a história do outro lado da história. Se Homero contou a história da partida, da viagem, do retorno, do estranho e do estrangeiro, a Penélope coube narrar "a odisseia da espera". À mulher cabe o papel do outro, do esquecido, do não dito, do silêncio, da espera, mas cabe a ela também - à mulher Penélope - em sua casa (e talvez exatamente por isso) a escrita da memória, tão entrelaçada está com a história do esquecimento, mesmo que a fidelidade esteja por um fio, como diz Ana Martins Marques em "Penélope II". O perigo com os riscos e rabiscos da escrita da memória e de seus esquecimentos não é menor.

\title{
Redes de amor e de linguagem
}

\author{
E o que é o amor \\ senão a pressa \\ da presa \\ em prender-se? \\ A pressa \\ da presa \\ em \\ perder-se?
}

Ana Martins Marques

O fio de Penélope pode nos levar a outro aspecto fundamental da obra de Ana Martins Marques: seu segundo livro, Da arte das armadilhas, tem uma arquitetura construída fio a fio pelos poemas, em uma sequência armada e escolhida, o que nos faz, por extensão, descartar a possibilidade de leitura fragmentária de um livro de poesia feita à revelia. Não à toa, o título desse livro, iniciado pela contração "da", nos sugere um manual de poesia, ou de leitura da poesia. Além disso, esse segundo livro dialoga com o primeiro, exatamente através da figura de Penélope. Há poemas com esse título; há outros em que ela figura como personagem; há ainda alguns em que ela é lembrança através de outras imagens. 
entre a casa

e o acaso

\author{
entre a jura \\ e os jogos \\ entre a volta \\ e as voltas \\ a morada \\ e o mar
}

penélopes

e circes

entre a ilha

e o ir-se (Marques, 2011, p. 9).

Esse texto, por exemplo, que abre $\mathrm{Da}$ arte das armadilhas, um poema sem título, espécie de epígrafe do livro, estabelece o fio entre o livro anterior e este, marcando ainda as dúvidas e ambiguidades da poesia, através da espera de Penélope (no primeiro verso dos cinco primeiros dísticos) e da viagem de Ulisses (no segundo verso dos cinco primeiros dísticos). Apenas no último dístico, o impasse parece ser somente de Ulisses, entre a ilha em que a feiticeira Circe o aprisionou e o desejo de "ir-se" (formando uma rima preciosa com "circes" do dístico anterior), voltar à viagem, mas dessa vez de retorno a casa e a Penélope, que aparecem aqui como metonímias. A casa é a ilha de Penélope, seu exílio, seu espaço de naufrágio, ${ }^{2}$ o que, de certo modo, mantém o impasse de Ulisses entre a casa-ilha (exílio também de Ulisses) e o ir-se.

\footnotetext{
${ }^{2}$ No Canto XXIII da Odisseia, é narrado o momento em que Penélope reconhece Ulisses, após o relato da construção do leito conjugal. A imagem de Penélope sorrindo abraçada ao seu esposo é a de um náufrago avistando a terra, enquanto Atena alonga a noite antes que chegue Eós-Aurora: "Falou. Aumenta-lhe o desejo de prantear:/ chorando, estreita a esposa, coração-primor./ Tal qual apraz ao náufrago a visão da terra,/ de quem Posêidon destruiu a nave sobre/ o mar, que a onda túrgida encalça e o vento,/ e poucos nadadores fogem do oceano/ cinza, salsugem abundante pelo corpo,/ no júbilo da praia, salvos do perigo,/ Penélope sorri ao vislumbrar o esposo,/ sem desatar do colo os braços pleniplenos./ Aurora dedirrósea, ao despontar, veria-os/ pranteando não tivera Atena olhos-azuis/ plano diverso: quase finda, alonga a noite,/ retém no mar Eós, trono de ouro:/ não consente que atrele os palafréns de pés/ velozes que a conduzam, Lampo e Faetonte" (Homero, 2012, Canto XXIII, versos 231-246).
} 
Ainda sobre a reflexão do fio estruturador do livro, convém que leiamos em conjunto aos demais os poemas seguintes. O primeiro, único sem título da segunda seção do livro, intitulada "Da arte das armadilhas", parece ser uma epígrafe desse segmento; o outro é o último poema do livro, com título homônimo:
A linguagem
sem cessar
arma
armadilhas
O amor
sem cessar
arma
armadilhas

Resta saber

se as armadilhas

são as mesmas

Mas como sabê-lo

se somos nós

as presas? (Marques, 2011, p. 31).

\section{Da arte das armadilhas}

O seu corpo para o meu:

seta,

precisamente

Inaudível

o mundo mudo

aciona o fecho

da flor

Há desilusão

mas não há

fuga

O caçador está preso

à presa (Marques, 2011, p. 83). 
As duas primeiras estrofes do primeiro poema transcrito apresentam uma única palavra que distingue uma estrofe de outra: na primeira, linguagem; na segunda, amor. O poema parece seguir, assim, um modelo de escrita muito comum na literatura trovadoresca medieval: o paralelismo das cantigas d'amigo, em que os versos são repetidos quase por inteiro, inclusive com a presença do refrão, à maneira dos cantos litúrgicos antifônicos.

Como nas cantigas d'amigo, as palavras alternadas têm forte relação semântica; nesse caso, linguagem e amor. E, na marcação rítmica dos versos, a relação é ainda maior: os dois primeiros das duas primeiras estrofes (a linguagem/ o amor) têm o mesmo número de sílabas métricas: três. Na primeira estrofe, a "linguagem" abre o verso também sonoramente: /a/ e exatamente na sílaba tônica; na segunda, o amor fecha o verso: /o/, também na sílaba tônica.

$\mathrm{Na}$ terceira estrofe, uma frase interrogativa indireta anuncia a dúvida da voz poética sobre o saber e o não saber, para culminar na única certeza, embora em uma frase interrogativa: a certeza que vem na última estrofe, a de que somos presas da linguagem e do amor.

Embora a palavra "presas" pertença ao gênero feminino, não é por essa palavra que se pode pensar na voz feminina desse poema, pois, em português, "presas" é um substantivo sobrecomum. A presença de uma voz feminina nesse texto mais se justifica pela semelhança com as cantigas d'amigo, em que a voz lírica é de uma mulher, embora tenham sido escritas por homens. Se essa semelhança justifica a voz feminina, é pela diferença que o texto se atualiza. $\mathrm{O}$ " $\mathrm{eu}^{\text {" feminino das cantigas }}$ d'amigo é transferido para um coletivo "nós": não é apenas o eu que fala no poema que é uma presa, mas o "nós", que pode também não ser só as mulheres. A subjetividade lírica daquelas cantigas, o saudosismo, a ausência do amado são aqui atenuados. A ideia de particularização, de confessionalismo, de forte relação entre "mulher escritora" e "assunto de mulher" é substituída por uma ideia de coletivismo. Assim, o poema se atualiza e também se atualizam as discussões sobre a literatura escrita por mulheres, que, de um particular limitado, passa a um caráter universal. A voz feminina tem, sim, eco universalizante.

Isso nos faz remeter ao livro Literature after feminism (2003), de Rita Felski, em que toma como ponto de partida a crítica dos críticos conservadores segundo a qual seu trabalho privilegiaria os estudos culturais e a mera sociologização dos estudos literários. Nesse livro, 
Felski se empenha na defesa da literatura e do valor atribuído ao literário pela crítica de caráter feminista, em negação à insistência em se afirmar que os intelectuais feministas não teriam compreensão racional do passado e do texto literário como forma. Literature after feminism é apenas o início de uma defesa que culminará em outro livro, também de sua autoria, intitulado Uses of literature, publicado em 2008. Sobre a defesa dos estudos literários e a respeito da relação preocupante - e insatisfatória - entre literatura e crítica panfletária e a ausência de percepção da universalidade dos textos literários, aspectos com que alguns críticos insistem em caracterizar a crítica feminista, a professora norte-americana refuta a ideia "either/or" e defende a relação "both/and" entre literatura e mundo social, culminando, por sua vez, com outra adição: estudos literários e estudos culturais.

Eu não tenho nenhuma dúvida de que toda essa conversa sobre literatura confundirá os leitores que acreditam que estamos na era dos estudos culturais. O que torna a literatura tão especial? Por que eu não falo mais acerca das abordagens feministas sobre música, moda ou filme? Na verdade, a maior parte do meu trabalho anterior lidou com o não canônico e, em alguns casos, os textos não literários sob uma perspectiva sociológica. Minha escrita é, assim, um excelente exemplo do declínio íngreme dos estudos literários em estudos culturais contra os quais os críticos conservadores sempre estão reclamando. E, como tal, posso parecer uma candidata altamente implausível para o trabalho de defender o valor literário dos estudos feministas. Acredito que essa contradição é mais aparente do que real. Ao contrário de alguns dos meus colegas, vejo estudos literários e estudos culturais mais que campos relacionados do que opostos (Felski, 2003, p. 20, tradução nossa).

Como ler um texto de autoria feminina, para muitos, infelizmente, ainda significa ler particularismos, abrimos parênteses à fala de Rita Felski e retomamos, a partir de agora, a insistente leitura da poesia da poetamulher Ana Martins Marques. No último poema do livro $\mathrm{Da}$ arte das armadilhas, transcrito anteriormente, de título homônimo a ele, a temática da relação entre linguagem e amor permanece, embora não haja nele uma única referência direta à linguagem, apenas ao amor e ao erotismo.

No verso 1, a palavra "para" é ambígua: preposição ou verbo parar? Ambos os sentidos se completam: um você se dirige a um eu, que é 
parado por uma seta precisa. A seta, que simboliza a presença de ErosCupido nesse poema, simboliza também a direção, o caminho do alvo a ser atingido, assumindo no texto o simbolismo do falo que atinge e para o corpo do eu lírico.

A parada do eu lírico na primeira estrofe se completa na segunda, pelo enjambement que parece acontecer entre "precisamente" e "inaudível". Sem ouvir a seta, o mundo se fecha em seu mutismo (som fechado /un/). O adjetivo "inaudível" também pode estar se referindo ao mundo mudo: aquele que nem tem voz nem é ouvido. Ainda na estrofe 2, é o mundo mudo e inaudível que "aciona o fecho da flor". "Flor" aqui, por um lado, sugere a genitália feminina, justificada pela leitura erótica do poema (pela relação que vínhamos estabelecendo entre falo e seta) e pela temática comum a Ana Martins Marques do euno-outro (seta em flor), do "eu consigo". Mas pode ter um sentido mais amplo, ainda que ligado a este.

O mundo mudo, inaudível, que não fala nem é ouvido, "aciona" (produz a ação, faz com que aconteça, inicia) o fecho da flor. O mundo é o agente da ação, enquanto a flor é passiva diante disso. Pelo enjambement com a estrofe 1 , a seta "inaudível" não atinge a flor que o "mundo mudo", parado, atônito, afônico trancou. A seta e o mundo seriam, pois, elementos que estariam numa relação metonímica - os dois vêm em direção à flor; os dois têm como alvo a flor; os dois provocam nela uma resposta, mesmo que cheguem em silêncio (inaudível/mudo). ${ }^{3}$

O resultado disso, dessa imobilidade (meu corpo parado), desse silêncio (seta inaudível, o mundo mudo, o mundo inaudível) e desse fechamento (a flor fechada em si mesma), é a desilusão, ainda marcada - na estrofe 3 - pela mesma imagem de imobilidade, silêncio, fechamento, que vinha sendo trabalhada ao longo do livro: trata-se de uma "desilusão" sem "fuga".

A culminância dessa ação/imobilidade está na estrofe final: caçador e presa estão juntos, na armadilha do amor (a seta/o mundo/o falo/o caçador; meu corpo/a flor/a genitália feminina/a presa) e na armadilha da linguagem (a seta/o mundo/a pena da escrita/o caçador; meu corpo/a flor/a palavra/a presa), e aqui deixamos a sugestão de leitura

\footnotetext{
${ }^{3}$ Convém registrar uma sutil alusão a Penélope na leitura desse poema: é a própria Penélope, no Canto XXI da Odisseia, quem retira o arco do quarto de Odisseu e propõe a prova do arco aos pretendentes.
} 
do poema transferindo a imagem erótica dos amantes para as palavras. Afinal, o título do poema é "Da arte das armadilhas", assim como o título do livro, cujo elemento estruturador está exatamente na relação intrínseca entre amor e linguagem pela incompletude e pelo desejo que os unem, pelas armadilhas que ambos - o amor e a linguagem impõem a suas presas, bem como a seus caçadores, com seus tecidos, suas tramas, suas redes em que amantes/poetas/leitores se prendem e se perdem, suas astúcias e suas "artes" (valendo a ambiguidade do termo) no mundo da poesia, no mundo também da vida.

\section{i like my body}

$$
\begin{gathered}
\text { i like my body when it is with your } \\
\text { body. } \\
\text { e. e. cummings }
\end{gathered}
$$

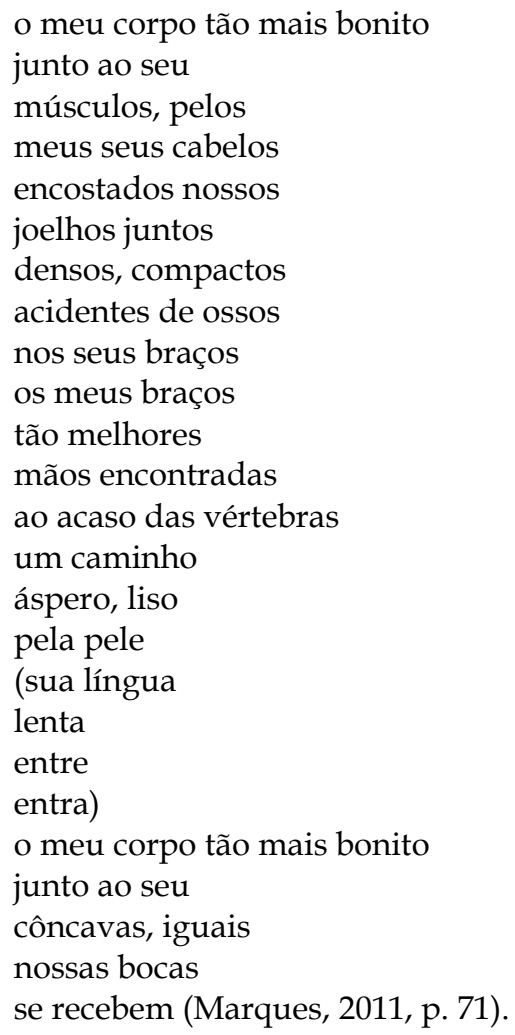


No poema acima, as palavras são trabalhadas de modo que a forma do texto é também corpo. A riqueza formal e a exploração visual do poema estão exatamente na representação do um-no-outro, em que a palavra do texto e o corpo dos amantes estão inextricavelmente interrelacionados: o enjambement, a separação por vírgulas de mesmos termos sintáticos em paralelismo, a substituição do pronome pessoal (eu) do título e da epígrafe para os pronomes possessivos $\mathrm{meu}(\mathrm{s}) / \mathrm{seu}(\mathrm{s}) /$ nossos, o uso dos parênteses, a polissemia do vocábulo "língua", a flutuação categorial entre preposição e verbo "entre", a repetição de versos idênticos ("o meu corpo tão mais bonito/junto ao seu"), a ausência do ponto-final. Todos esses aspectos acentuam o erotismo do texto e a preocupação com a construção textual como rede, tecido, malha de Penélope.

Retomando a imagem de Penélope, há ainda um poema do livro $D a$ arte das armadilhas, com esse título, que convém ser mencionado:

\section{Penélope}

Teu nome

espaço

meu nome

espera

teu nome

astúcias

meu nome

agulhas

teu nome

nau

meu nome

noite

teu nome

ninguém

meu nome 
também

num só gesto

reconhecer-te

e perder-te (Marques, 2011, p. 45-6).

Chamam a atenção do leitor as palavras que compõem os segundos versos das oito primeiras estrofes, que, além de estarem ligadas por seu componente lúdico e material exemplificado pelo palavra-puxa-palavra (espaço/espera), pelas rimas toantes (astúcias/agulhas), pela aliteração (nau/noite), pelas rimas consoantes (ninguém/também), também prenunciam - se lidas em conjunto - o desfecho do poema. No espaço da espera de Penélope, nas astúcias de suas agulhas, em sua nau do pensar à noite (a viagem não marítima de Penélope, a viagem marítima da poesia com os perigos do mar e seus barcos bêbados), enquanto fiava para guardar na memória o ninguém que também é, o enlace de nomes entre "tu" e "eu", o "teu" e o "meu", há uma única de tão poucas certezas: em matéria de linguagem e amor, está por um fio, no abismo de uma linha ou verso, o gesto de reconhecer e perder.

Em espera e em exílio, a Penélope tecedora e astuciosa se torna a guardiã da memória feita e desfeita de suas histórias e seus esquecimentos, assim como também a poesia que, na astúcia e razão de suas falas e silêncios, é sentida e pensada, com o coração e o cérebro, conforme diz Abrams, lembrando-nos do quanto ela, em sua materialidade e não materialidade, está próxima do humano: essa rede de "pensamôr" ética e poética que Penélope e Ana Martins Marques fiam, desfiam e desafiam "coraçãomente". Afinal, como escreve Ana no poema "Lugar para pensar":

Uma coisa que nunca entendi é por que

em geral se acredita que o poema

não é lugar para pensar (Marques, 2009, p. 26).

\section{Referências}

ABRAMS, M. H. (2012). The fourth dimension of a poem and other essays. New York; London: W. W. Norton \& Company. 
ARENDT, Hannah (2010). A vida do espírito: o pensar, o querer, o julgar. Tradução de Cesar Augusto R. de Almeida, Antônio Abranches e Helena Martins. 2. ed. Rio de Janeiro: Civilização Brasileira.

FELSKI, Rita (2003). Literature after feminism. London; Chicago: The University of Chicago Press.

FELSKI, Rita (2008). Uses of literature. Malden: Blackwell Publishing.

HOMERO (2012). Odisseia. Edição bilíngue. Tradução, posfácio e notas de Trajano Vieira. São Paulo: 34.

MARQUES, Ana Martins (2009). A vida submarina. Belo Horizonte: Scriptum.

FELSKI, Rita (2011). Da arte das armadilhas. São Paulo: Companhia das Letras.

ROSA, João Guimarães (2005). Substância. In: ROSA, João Guimarães. Primeiras estórias. Rio de Janeiro: Nova Fronteira.

Recebido em setembro de 2014.

Aprovado em dezembro de 2014.

\section{resumo/abstract}

\section{A razão ética e poética nos poemas de Ana Martins Marques}

Anélia Montechiari Pietrani

Na obra da jovem poeta mineira Ana Martins Marques, autora de A vida submarina e Da arte das armadilhas, a sensibilidade feminina e a disciplina estética são marcas significativas. Ler seus poemas, especialmente seus metapoemas, e a arquitetura de seus textos faz-nos situar a novíssima poesia brasileira na atualidade do século XXI, de modo a refletir sobre o papel, o valor e o lugar da poesia na contemporaneidade, como potência e busca de significados em que confluem a razão ética e a poética.

Palavras-chave: autoria feminina, ética, poética, Ana Martins Marques.

\section{The ethical and poetic reason in the poems of Ana Martins Marques}

Anélia Montechiari Pietrani

In the work of the young poet Ana Martins Marques, author of A vida submarina and $\mathrm{Da}$ arte das armadilhas, the feminine sensibility and aesthetic discipline are 
significant marks. Reading her poems, especially her metapoems, and the architecture of her texts make us situate the new Brazilian poetry at the present of the twenty-first century, to reflect on the role, value and place of poetry in contemporary times, as power and search of meanings at which the ethical and the poetic reason converge.

Palavras-chave: female author, ethics, poetic, Ana Martins Marques. 